\title{
THE ASSOCIATION OF SELF-PERCEIVED EATING ACCULTURATION ON FATIGUE OR DEPRESSIVE SYMPTOMS AMONG MIGRANT INDONESIAN WOMEN IN TAIWAN WITH MENTAL/PHYSICAL DISTRESS HISTORY
}

\author{
Palupi, Khairizka Citra ${ }^{1 *}$, Chang, Jung-Su${ }^{2}$ and Shih, Chun-Kuang ${ }^{2}$ \\ ${ }^{1}$ Esa Unggul University, Indonesia \\ ${ }^{2}$ Taipei Medical University, Taiwan
}

\begin{abstract}
Migrant workers have been associated with increased vulnerability to fatigue and depression. However, it remains unknown whether self-perceived acculturation among women migrant workers (WMWs) affects fatigue and depressive symptoms in relation to mental/physical distress (MPD) history. Methods and Study Design: 235 Indonesian women migrants aged 20-50 years who were working in Taipei were studied. Self-perceived acculturation, dietary acculturation, body mass index, hemoglobin, fatigue and depressive symptoms were assessed. Results: The prevalence of fatigue or depressive symptoms was 40.8\%. WMWs with MPD history are increased risk for fatigue (OR: 5.584 (2.694-11.574)) and depression (OR: 2.625 (1.242-5.549)) and they acculturate differently than women without MPD history. Among women with MPD history, a better self-perceived eating habit was associated with lower risk (OR: $0.132(0.018-0.980)$ for fatigue or depressive symptoms compared with no changes. Conclusion: WMWs with self-reported mental/physical distress (MPD) history (fatigue or depression) were more likely to develop fatigue and depressive symptoms compared with women with no MPD history and a better self-perceived eating habit may protect them to develop on fatigue or depressive symptoms.
\end{abstract}

Keywords: Self-perceived eating, Acculturation, Fatigue, Depressive, Indonesian Female Migrant Workers

\section{Introduction}

The number of international migration worldwide has continued to grow which international migrant originating in Asia recorded the largest increase (UN, 2016). Migrant women account for almost a half of migrant workers worldwide (UN, 2016). Globally, working on social welfare such as domestic work and caregiver is a much higher source of employment for migrant (ILO, 2015). In Taiwan, migrant Indonesian women represent the major sources of migrant women working in social welfare which account more than 75\% (MoLT, 2018). Migrant workers have been associated with increased vulnerability to fatigue and depression (Abrol et.al. 2008; Lee et.al. 2012; Lee et.al.2009; Liu et.al. 2011). In addition, being women and having history of fatigue and depression may increase risk for fatigue and depression (Ridsdale et.al. 2011; NIMH, 2018; Sharpe and Wilks, 2002; Monroe et.al. 2014). Untreated fatigue and depression among workers may affect work performance, quality of life, mental and body health (Liu et.al. 2011; Kant et.al. 2007; Penninx et.al. 2013).

Phases of migratory consist of five phases including pre-departure, travel, destination, interception and return phase (IOM, 2019). The destination phase occurs when migrant workers settle in the host country temporarily. In this period, migrant workers may face chronic and acute acculturative stressors. Long separation from their family and new sociocultural norms may lead to loneliness, depression and unsafe risk-taking behavior in the host country (IOM, 2019). The prevalence of depression among migrant workers $25.1 \%$ to $34 \%$ has been reported (Lee et.al. 2012; Lee et.al. 2009; Al-Maskari et.al. 2011). Whereas, the prevalence of fatigue among 
migrant women was $27.8 \%$ (Palupi et.al. 2017). Depression and fatigue have consistently been found strongly associated across different healthcare settings and population (Skapinakis et.al. 2003). Condition surrounding migration process may affect the development of fatigue and depression among migrant workers (IOM, 2019). They may face acculturation which is a process to adopt the beliefs, habit and behaviors of their host country (Popovic-Lipovac and Strasser, 2013). Several risk factors for depression and fatigue have been elucidated among migrant workers such as job stress, physical environment, occupational climate, dietary acculturation, acculturative stress and job demand (Lee et.al. 2012; Lee et.al. 2009; Palupi et.al. 2017). Although some components of acculturation has been identified as risk factor for depression and fatigue, the relationship of self-perceived acculturation and having history of fatigue or depression on the development of fatigue or depressive symptoms among migrant workers remain unknown. Previous study suggests that a larger perceived acculturation gap may have negative outcome on behavior an body health (Buki et.al. 2003; Kaholokula et.al. 2010). Inversely, higher acculturation with environment may reduce depressive symptoms, perceived stress and alienation among former Sovyet immigrants (Nicholson et.al. 2013). Taken together, it is necessary to investigate (1) whether WMWs with self-reported mental/physical distress (MPD) history (fatigue or depression) were more likely to develop fatigue and depressive symptoms compared with women with no MPD history, and (2) to identify risk factors associate with fatigue or depressive symptoms in relation to MPD history.

\section{Methods}

\section{Study design and participants}

This cross-sectional study was undertaken in Taipei City, Taiwan. A total of 235 Indonesian WMWs, aged 2050 years old were recruited using convenience sampling in multi setting such as Taipei Medical University, public parks in Taipei, Indonesian migrant workers community event/meeting, mosques and Taipei Main Station from December 2015 - February 2015. The response rate was 94\%. Before initiating the data collection and biochemistry measurement, subjects were excluded if they had: (1) self-reported chronic diseases (e.g. cancer, type 2 diabetes, hypertension, and heart diseases), fever, pregnancy, breast feeding, consumed iron supplementation within previous 3 month, consumed anti-depressant drugs or anti-hypertensive drugs, having gastrointestinal disorders, severe bleeding and parasitic infections (e.g. inflammatory bowel disease, history of gastric ulcer, red blood cell disorders, menorrhagia, hemorrhoids, hematuria, uterine fibroids, malaria, and worm infection), (2) menopause, and (3) Taiwan resident visa. This study was conducted according to the guidelines laid down in the Declaration of Helsinki and all procedures involving human subjects were approved by Taipei Medical University Institutional Review Board (201409045). Participants provided informed consent and patient anonymity was preserved.

\section{Data collection and biochemical measurements}

Socio-demographic data such as age, income per month, length of work permits, family member they serve, type of jobs, and education level were obtained. Body weight was measured using digital weight scale from Mancorp Enterprises Ltd and recorded to the nearest $0.5 \mathrm{~kg}$ in light clothing, footwear removed and pockets emptied. Body height was determined by subject. Body Mass Index (BMI) was calculated as weight $(\mathrm{kg}) / \mathrm{height}$ (m2). Overweight was defined as BMI between $>23 \mathrm{~kg} / \mathrm{m} 2$ to $24.9 \mathrm{~kg} / \mathrm{m} 2$ and obesity was defined as BMI $>25$ $\mathrm{kg} / \mathrm{m} 2$ (WHO, 2000). Acculturation was measured by two parameters. Dietary acculturation and self-perceived acculturation were evaluated via a face to face interview by the investigator. Examples of dietary acculturation question were as follows: (1) What is the most common cooking method used in Taiwan?, (2) What is the most food you eat in Taiwan?, and (3) Do you like Taiwanese food?. Example of self-perceived acculturation questions were as follows: (1) How have your feeling changed since living in Taiwan?, (2) How have your eating habits changed since living in Taiwan?, (3) Has your health status changed since living in Taiwan?. Selfreported history of mental and physical distress (fatigue or depressive symptoms) was obtained. Current physical distress (fatigue) was evaluated using Brief Fatigue Inventory (BFI) via oral interview. BFI has been 
identified as a valid and reliable uni-dimensional instrument to assess fatigue severity and the interference with life activities within previous 24 hours (Mendoza et al., 1999). In the present sample, the Cronbach's alpha (0.89) met the standard criteria of acceptability. Mental distress (depressive symptoms) was also assessed using an Indonesian version of Beck Depression Inventory- II (BDI-II) (Ginting et.al. 2013). BDI-II has been validated and is reliable for Indonesian general population (Cronbach's alpha 0.90). BDI is one of the most widely used questionnaires to assess depressive symptoms and severity in general population (Aalto et al., 2012; Smarr and Keefer 2011).

Erythropoiesis status was determined using HemoCue®201+ hemoglobin photometer from HemoCue AB. This instrument is generally recommended in public health surveys to determine the prevalence of anaemia (WHO, 2001). The HemoCue ${ }^{\circledR}$ system is based on the cyanmethemoglobin method and has been shown to be stable and durable in the field settings (WHO, 2011). According to the 2001 WHO report, anaemia severity in reproductive aged women can be defined based on Hb levels: (1) Hb level $\geq 12 \mathrm{~g} / \mathrm{dL}$ for non-anaemia, (2) Hb level between 11-11.9 g/dL for mild anaemia, (3) $\mathrm{Hb}$ level between 8-10.9 g/dL for moderate anaemia and (4) $\mathrm{Hb}$ level< 8 $\mathrm{g} / \mathrm{dL}$ for severe anaemia (WHO, 2011).

\section{Statistical analysis}

Statistical Analysis was performed using IBM SPSS 20.0 version. Categorical data were presented as number and percentage, and tested by chi-square test. Continuous data were presented as mean (standard deviation) and tested by 2 sample t-test. Differences between two independent samples were analyzed by the Mann-Whitney U-test for the non-parametric data. Logistic regression models were used to estimate the odds ratio (OR) of dependent variable and independent effects of known risk factor at 95\% confidence interval (CI). To further characterize the relationships between risk factors in relation to fatigue or depressive symptoms, a binary logistic model was employed. p-value less than 0.05 were set as statistically significant.

\section{Results}

\section{Baseline characteristics}

A total of 235 WMWs were enrolled in this study. Forty one (17.4\%) women had MPD history (Table.1). There was difference on the mean age between women with and without MPD history $(33.02+7.00$ and 30.07 + 5.82, respectively). However, there were no differences on remaining socio-economic and demographic factors. The overall prevalence of fatigue, depressive symptoms and anemia was $34.89 \%, 19.57 \%$ and $25.53 \%$, respectively. Specifically, the prevalence of fatigue or depressive symptoms was $40.8 \%$.

Table 1 shows women with MPD history had higher prevalence rate of fatigue $(68.3 \%)$ and depressive symptoms (34.1\%) compared with women without MPD history. Univariate analysis showed women with MPD history had 5.584 times $(2.694-11.574))$ and 2.625 times $(1.242-5.549)$ higher risk for fatigue and depressive symptoms compared with women with no MPD history. Women with MPD history had lower preference rate of preferring Taiwanese food compared with women without MPD history, $39 \%$ and $59 \%$, respectively (Table 1). A poor rating of self-perceived feeling and health status was also observed in women with MPD history compared with women without MPD history.

\section{Risk factors associate with fatigue or depressive symptoms in relation to MPD history}

We next investigate factors associate with fatigue or depressive symptoms in relation to MPD history. Among women without MPD history, the type of job, cooking methods, self-perceived feeling, and selfperceived health status were significantly associated with fatigue or depressive symptoms (all $\mathrm{p}<0.05)($ Table 2). There was no association between preference of Taiwanese foods and fatigue or depressive symptoms was 
also observed $(\mathrm{p}=0.083)$. Among women with MPD history, there were no statistically significant difference $(\mathrm{P}>0.05)$ between fatigue or depressive symptoms and erythropoiesis, self-perceived feeling, and self-perceived eating habit were observed ( $\mathrm{p}=0.069, \mathrm{p}=0.077$, and $\mathrm{p}=0.087$, respectively).

Among women with fatigue or depressive symptoms, women with MPD history were slightly younger (29.47 yrs versus 32.2 yrs; $\mathrm{p}=0.087$ ) and were less likely to have anemia compared with women without MPD history; $10 \%$ and $31.8 \%$, respectively $(\mathrm{p}=0.042)$. In addition, women with MPD history were more likely to report worse health status compared with women without MPD history; $33.3 \%$ and $15.2 \%$, respectively.

\section{Odds ratios of the risk factors on fatigue or depressive symptoms in relation to MPD history}

Among women with MPD history, a better self-perceived eating habit was associated with lower risk (OR: $0.132(0.018-0.980)$ for fatigue or depressive symptoms compared with no changes after adjusting for covariates (Table 3). Among women without MPD history, deep and stir frying (steaming/boiling compared with deep/stir frying: OR: $8.837(2.022$ - 38.617)) and self-perceived feeling sad and weak (no changes compared with feeling sad and weak: OR: 3.742 (1.371-10.21) had significant effects on fatigue or depressive symptoms $(\mathrm{P}<0.05)$. In addition, a borderline odds ratios for job category (caregiver compared with noncaregiver: OR: $3.94(0.992-15.624)$ and preference Taiwanese (no/slightly compared with yes: OR 0.51(0.2541.023) was found in women without MPD history (Table 3).

\section{Discussion}

This present study is the first cross-sectional study to investigate effect of acculturation on the development of fatigue or depressive symptoms in relation to mental/physical distress (MPD) history. Our study showed that women with MPD history are more likely to develop fatigue and depressive symptoms and they appear to acculturate differently than women without MPD history. Deep/stir frying is the major predictor for fatigue or depressive symptoms among WMWs without MPD history. Meanwhile, self-perceived better eating habits protects against the development of fatigue or depressive symptoms among women with MPD history. Our study suggests that women without MPD history should avoid the use of deep/ stir frying as means of food preparation methods in order to prevent fatigue or fatigue/depressive symptoms. By contrast, women with MPD history are encouraged to consume a variety of healthy food in order to protect against the development of fatigue and depressive symptoms.

Our finding suggested that better self-perceived eating habit protects women with MPD history from mental and physical distress. Although self-perceived better eating habits can be a diverse and complex, the majority of findings suggest that (1) fruit and vegetables, (2) vitamin and mineral, (3) animal food are the major food sources that closely relate to perception of eating habits (Paquette 2005; Velazquez et.al. 2011). In addition, self-perceived eating habits were associated with diseases outcome such as obesity and diabetes (Gellar et al., 2007; Lake et al., 2007). Our study raise the possibility that having a better self-perceived eating habit in the host country may protect female migrant workers from the development of fatigue or depressive symptoms, particularly among female with MPD history.

WMWs with MPD history were more likely to be younger, lower income, shorter length of work permits and higher job burden. These indicate that they may have less work experience. WMWs with MPD history had a lower percentage of preference of Taiwanese food (39\% versus 59\%) compared with women with MPD history. This suggests they did not well acculturate in terms of diet. A poor self-perceived acculturation was also associated with women with MPD history. They had higher rate of feeling sad and weak and having a worse self-perceived health status compared with women without MPD history. For women without MPD history, they seem to adapt the habits and behavior the host country. They also followed the dietary pattern of the host country. This finding is in keeping with most studies in America and Europe which assessing dietary acculturation in migrants in which migrant tend to adapt the dietary pattern in the host country (Popovic- 
Lipovac and Strasser 2013). In conclusion, our study suggested a poor acculturation may lead to higher vulnerability to develop fatigue or depressive symptoms, particularly for women with MPD history (Sharpe and Wilks 2002).

The major predictor for fatigue and depressive symptoms among WMWs without MPD history are (1) deep and stir frying and (2) self-perceived feeling sad and weak. Literatures suggest that deep and stir frying is associated with fried food, dietary fat and advances glycation ends products formation (AGEs) ( Fillion and Henry 1998; Logan and Jacka 2014). Fried food and dietary fat have been identified closely related to negative quality of life and depression (Tung et.al. 2011). In addition, cooking practices in relation to AGEs have been proposed may play a role in mental disorders (Logan and Jacka 2014). Taken together, this suggests that fried food, dietary fat and AGEs which associated with deep and stir frying may affect the development of fatigue or depressive symptoms. Having a self-perceived acculturation (feeling sad and weak) since migrant in the host country was also a good indicator to predict fatigue or depressive symptoms since this is one of symptom related to both fatigue and depressive symptoms (Sharpe and Wilks 2002; WHO 2012 ).

Among women with fatigue and depressive symptoms, women with MPD history were less likely to have anemia compared with women without MPD history (10\% versus 31.8\%). Therefore, anemia seems a protective effect against the development of fatigue and depressive symptoms among women with MPD history. Recent cohort study among young adults by Milligen and colleagues have evaluated that current depressive and/or anxiety disorders was not significantly associated with higher odds ratio for anemia. By contract, current depressive and/or anxiety disorders have a significant higher odds ratio for having Hb 14.1-15.00 g/dL (OR= $1.26,95 \% \mathrm{CI}=1.00-1.59)$ compared with healthy controls $(\mathrm{Hb} 12.1-14.00 \mathrm{~g} / \mathrm{dL})$. The odd was even larger for those with $\mathrm{Hb}>15.1 \mathrm{~g} / \mathrm{dL}$ compared with healthy controls, but this was not statistically significant (Lever-van Milligen et al., 2014). Although, earlier studies have suggested that fatigue and depressive symptoms as symptoms of anemia (USDH 2011) but most of studies have been conducted in clinical/elderly patients (Cella 1998; Holzner et al., 2002; Onder et al., 2005).Inflammation is the underlying risk factor among clinical/elderly patients to develop anemia, fatigue and depressive symptoms. Therefore, it is difficult to address that fatigue and depressive symptoms may affect anemic women in our study population. Some individuals who are not suffer from chronic inflammation may have no experience of fatigue and depressive symptoms if anemia is mild or moderate (USDH 2011). WMWs with MPD history appear to acculturate differently than women without MPD history. WMWs with MPD history are encouraged to acculturate with Taiwanese environment. WMWs without MPD history should avoid the use of deep/stir frying as means of food preparation methods in order to prevent fatigue and depressive symptoms.

\section{Conclusion}

WMWs with self-reported mental/physical distress (MPD) history (fatigue or depression) were more likely to develop fatigue and depressive symptoms compared with women with no MPD history and a better selfperceived eating habit may protect them to develop on fatigue or depressive symptoms.

\section{Author Contributions}

$\mathrm{KCP}$ participated in the design study, data collection, data analyses and writing initial manuscript. CKS: conducted data analyses, interpretation and review manuscript. JSC: conceptualized and designed the study, drafted the initial manuscript, and approved the final manuscript. All authors have read and approved the final version of the manuscript and agree with the order of presentation of the authors. 


\section{Acknowledgments}

We gratefully acknowledge all study participants and thank the staff at the Biostatistics Center, Taipei Medical University for the assistance with data analysis and interpretation, Adi Lukas Kurniawan for their assistance in formatting final manuscript.

\section{References}

Aalto, A.M., Elovainio, M., Kivimaki, M., Uutela, A., and Pirkola, S, 2012, The Beck Depression Inventory and General Health Questionnaire as measures of depression in the general population: a validation study using the Composite International Diagnostic Interview as the gold standard. Psychiatry Res, 197 (1-2), 163-171.

Abrol, A., Kalia, M., Gupta, B., and Sekhon, A., 2008, Maternal health indicators among migrant women construction workers. Indian J Community Med. 33(4), 276-277.

Al-Maskari, F., Shah, S.M., Al-Sharhan, R., Al-Haj, E., Al-Kaabi, K., Khonji, D., Schneider, J.D., Nagelkerke, N.J. and Bernsen, R.M., 2011, Prevalence of depression and suicidal behaviors among male migrant workers in United Arab Emirates. Journal of immigrant and minority health, 13(6), 1027.

Buki, L.P., Ma, T.C., Strom, R.D. and Strom, S.K., 2003, Chinese immigrant mothers of adolescents: Selfperceptions of acculturation effects on parenting. Cultural diversity and ethnic minority psychology, 9(2), p.127.

Cella, D., 1998, Factors influencing quality of life in cancer patients: anemia and fatigue. Semin Oncol, 3(7), 43-46.

Fillion, L. and Henry, C.J.K., 1998, Nutrient losses and gains during frying: a review. International journal of food sciences and nutrition, 49(2), 157-168.

Gellar, L.A., Schrader, K. and Nansel, T.R., 2007, Healthy eating practices. The Diabetes Educator, 33(4), pp.671-679

Ginting, H., Näring, G., van der Veld, W.M., Srisayekti, W., and Becker, E.S., 2013, Validating the Beck Depression Inventory-II in Indonesia's general population and coronary heart disease patients. International Journal of Clinical and Health Psychology, 13(3), 235-242.

Holzner, B., Kemmler, G., Greil, R., Kopp, M., Zeimet, A., Raderer, M., Hejna, M., Zöchbauer, S., Krajnik, G., Huber, H. and Fleischhacker, W.W., 2002. The impact of hemoglobin levels on fatigue and quality of life in cancer patients. Annals of Oncology, 13(6), 965-973.

INTERNATIONAL ORGANIZATION FOR MIGRATION (IOM), Asian Labor Migrant and Health: Exploring Policy Routes Issue in Brief, Date of access: 03/07/2019. https://www.migrationpolicy.org/research/asian-labormigrants-health

INTERNATIONAL LABOUR ORGANIZATION (ILO), ILO Labour Migration Health, 2015, Migrant domestic workers across the world: Global and regional estimates.

Kant, I., Jansen, N.W. and Huibers, M.J., 2007, Course, consequences and treatment of prolonged fatigue among workers: an overview of findings from the Maastricht Cohort Study. Tijdschrift voor psychiatrie, 49(8), 547-554.

Kaholokula, J.K.A., Iwane, M.K. and Nacapoy, A.H., 2010, Effects of perceived racism and acculturation on hypertension in Native Hawaiians. Hawaii Medical Journal, 69(5 suppl 2), 11.

Lake, A.A., Hyland, R.M., Rugg-Gunn, A.J., Wood, C.E., Mathers, J.C. and Adamson, A.J., 2007, Healthy eating: perceptions and practice (the ASH30 study). Appetite, 48(2), 176-182.

Lee, H., Ahn, H., Miller, A., Park, C.G. and Kim, S.J., 2012, Acculturative stress, work-related psychosocial factors and depression in Korean-Chinese migrant workers in Korea. Journal of occupational health, 54(3), 206214.

Lee, S.W., Kim, K.S., Kim, T.G., Ryu, H.W., Lee, M.Y., Won, Y.L. and Song, Y.H., 2009, The Relationship between Job Stress and Depressive Symptoms in Migrant Workers in Kyung-gi Province in Korea. Korean Journal of Occupational and Environmental Medicine, 21(1), 76-86. 
Lever-van Milligen, B.A., Vogelzangs, N., Smit, J.H. and Penninx, B.W., 2014, Hemoglobin levels in persons with depressive and/or anxiety disorders. Journal of psychosomatic research, 76(4), 317-321.

Liu, Y., Liu, L., Sun, W., Shan, G.L. and Wang, Z.Z., 2011, Survey on the quality of life and related factors among farmer workers in Hubei province. Zhonghua liu xing bing xue za zhi= Zhonghua liuxingbingxue zazhi, 32(5), 481-484.

Logan, A.C. and Jacka, F.N., 2014. Nutritional psychiatry research: an emerging discipline and its intersection with global urbanization, environmental challenges and the evolutionary mismatch. Journal of Physiological Anthropology, 33(1), 22.

Mendoza, T.R., Wang, X.S., Cleeland, C.S., Morrissey, M., Johnson, B.A., Wendt, J.K., and Huber, S.L., 1999, The rapid assessment of fatigue severity in cancer patients: use of the Brief Fatigue Inventory. Cancer, 85(5), 1186-1196.

MINISTRY OF LABOUR TAIWAN, 2018, Foreign workers in Productive Industries and Social Welfare 2018.

Monroe, S.M., Slavich, G.M. and Gotlib, I.H., 2014, Life stress and family history for depression: The moderating role of past depressive episodes. Journal of psychiatric research, 49, 90-95.

Nicholson, L.M., Miller, A.M., Schwertz, D. and Sorokin, O., 2013, Gender differences in acculturation, stress, and salivary cortisol response among former Soviet immigrants. Journal of immigrant and minority health, 15(3), 540-552.

NATIONAL INSTITUTE OF MENTAL HEALTH, Depression, Date of access: 03/07/2018, https://www.nimh.nih.gov/health/topics/depression/index.shtml

Onder, G., Penninx, B.W., Cesari, M., Bandinelli, S., Lauretani, F., Bartali, B., Gori, A.M., Pahor, M. and Ferrucci, L., 2005, Anemia is associated with depression in older adults: results from the InCHIANTI study. The Journals of Gerontology Series A: Biological Sciences and Medical Sciences, 60(9), 1168-1172.

Palupi, K.C., Shih, C.K. and Chang, J.S., 2017, Cooking methods and depressive symptoms are joint risk factors for fatigue among migrant Indonesian women working domestically in Taiwan. Asia Pacific journal of clinical nutrition, 26(Supplement), S61.

Paquette, M.C., 2005, Perceptions of healthy eating: state of knowledge and research gaps. Canadian Journal of Public Health/Revue Canadienne de Sante'e Publique, S15-S19.

Penninx, B.W., Milaneschi, Y., Lamers, F. and Vogelzangs, N., 2013, Understanding the somatic consequences of depression: biological mechanisms and the role of depression symptom profile. BMC medicine, 11(1), 129.

Popovic-Lipovac, A. and Strasser, B., 2013, A Review on Changes in Food Habits Among Immigrant Women and Implications for Health. J Immigr Minor Health, 17(2), 582-590.

Ridsdale, L., Evans, A., Jerrett, W., Mandalia, S., Osler, K. and Vora, H., 1993. Patients with fatigue in general practice: a prospective study. Bmj, 307(6896), pp.103-106.

Sharpe, M. and Wilks, D., 2002. Fatigue. Bmj, 325(7362), pp.480-483.

Skapinakis, P., Lewis, G. and Meltzer, H., 2003. Clarifying the relationship between unexplained chronic fatigue and psychiatric morbidity: results from a community survey in Great Britain. International Review of Psychiatry, 15(1-2), pp.57-64.

Smarr, K.L. and Keefer, A.L., 2011, Measures of depression and depressive symptoms: Beck Depression Inventory-II (BDI-II), Center for Epidemiologic Studies Depression Scale (CES-D), Geriatric Depression Scale (GDS), Hospital Anxiety and Depression Scale (HADS), and Patient Health Questionnaire-9 (PHQ-9). Arthritis care \& research, 63(S11), S454-S466.

Tung, H.H., Tseng, L.H., Wei, J., Lin, C.H., Wang, T.J. and Liang, S.Y., 2011. Food pattern and quality of life in metabolic syndrome patients who underwent coronary artery bypass grafting in Taiwan. European Journal of Cardiovascular Nursing, 10(4), pp.205-212.

U.S. Department of Health and Human Services, National Institutes of Health, Your Guide to Anemia, Date of access: 03/07/2018. https://www.nhlbi.nih.gov/files/docs/public/blood/anemia-yg.pdf 
United Nation, International Migration Report, Date of access: 03/07/2018. https://www.un.org/en/development/desa/population/migration/publications/migrationreport/docs/MigrationRep ort2015_Highlights.pdf

Velazquez, C.E., Pasch, K.E., Ranjit, N., Mirchandani, G. and Hoelscher, D.M., 2011. Are adolescents' perceptions of dietary practices associated with their dietary behaviors?. Journal of the American Dietetic Association, 111(11), pp.1735-1740.

WORLD HEALTH ORGANIZATION, International Association for the study of obesity, Organization, Redefining Obesity and Its Treatment, Date of access: 03/07/2018, http://www.wpro.who.int/nutrition/documents/docs/Redefiningobesity.pdf

WORLD HEALTH ORGANIZATION, Iron Deficiency Anemia: Assessment, Prevention and Control, Date of access: $\quad$ 03/07/2018, https://www.who.int/nutrition/ publications/micronutrients/anaemia_iron_deficiency/WHO_NHD_01.3/en/

WORLD HEALTH ORGANIZATION, Haemoglobin concentrations for the diagnosis of anaemia and assessment of severity, Date of access: 03/07/2018, https://www.who.int/vmnis/ indicators/haemoglobin/en/

WORLD HEALTH ORGANIZATION, Depression, A Global Public Health Concern, Date of access: 03/07/2018, https://www.who.int/mental_health/management/_depression/ who_paper_depression_wfmh_2012.pdf 
Table 1. Baseline characteristics according to the present of mental/physical health history

\begin{tabular}{|c|c|c|c|}
\hline \multirow{2}{*}{ Variables } & \multicolumn{2}{|c|}{ Mental/Physical Health History } & \multirow{2}{*}{$\mathrm{p}$-value } \\
\hline & Absent & Present & \\
\hline Numberc & $194(82.6)$ & $41(17.4)$ & \\
\hline \multicolumn{4}{|l|}{ Socio-economic and demographic factors } \\
\hline Age $(y r s)^{a}$ & $33.02(7.00)$ & $30.07(5.82)$ & 0.013 \\
\hline Income (Taiwanese dollars) ${ }^{\mathrm{a}}$ & $\begin{array}{l}16121.63 \\
(2401.32)\end{array}$ & $15232(3347.22)$ & 0.369 \\
\hline Length of work permits (months) ${ }^{\mathrm{a}}$ & $53.10(32.04)$ & $47.80(29.45)$ & 0.371 \\
\hline Family member they serve ${ }^{b}$ & $3(1,4)$ & $3(1,5)$ & 0.633 \\
\hline Type of jobc & & & 1.000 \\
\hline Caregiver & $182(93.8)$ & $39(95.1)$ & \\
\hline Non-caregiver & $12(6.2)$ & $2(4.9)$ & \\
\hline Education level $^{\mathrm{c}}$ & & & 0.239 \\
\hline Elementary school & $22(11.3)$ & $7(17.1)$ & \\
\hline Junior high school & $103(53.1)$ & $16(39.0)$ & \\
\hline$>$ Senior high school & $69(35.6)$ & $18(43.9)$ & \\
\hline Religion & & & 1.000 \\
\hline Islam & $193(99.5)$ & $41(100.0)$ & \\
\hline Non-Islam & $1(0.5)$ & $0(0.0)$ & \\
\hline \multicolumn{4}{|l|}{ Health status } \\
\hline Fatigue status & & & $<0.0001$ \\
\hline Non-fatigue & $140(72.2)$ & $13(31.7)$ & \\
\hline Fatigue & $54(27.8)$ & $28(68.3)$ & \\
\hline Depressive symptoms ${ }^{c} \dagger$ & & & 0.016 \\
\hline Absent & $162(83.5)$ & $27(65.9)$ & \\
\hline Present & $32(16.5)$ & $14(34.1)$ & \\
\hline Hemoglobin $(\mathrm{gr} / \mathrm{dl})^{\mathrm{a}}$ & $12.74(1.54)$ & $12.91(1.31)$ & 0.535 \\
\hline Erythropoiesis $₫$ & & & 0.332 \\
\hline Normal & $141(72.7)$ & $34(82.9)$ & \\
\hline Mild anemia & $30(15.5)$ & $3(7.3)$ & \\
\hline Moderate anemia & $23(11.9)$ & $4(9.8)$ & \\
\hline Body mass index $(\mathrm{kg} / \mathrm{m} 2)^{\mathrm{a}}$ & $23.63(3.35)$ & $23.07(2.35)$ & 0.402 \\
\hline Change body weight since living Taiwan ${ }^{\mathrm{c}}$ & & & 0.203 \\
\hline Decreased & $45(23.2)$ & $15(36.6)$ & \\
\hline No changes & $46(23.7)$ & $8(19.5)$ & \\
\hline Increased & $103(53.1)$ & $18(43.9)$ & \\
\hline \multicolumn{4}{|l|}{ Dietary Acculturation } \\
\hline Cooking methods used in Taiwanc & & & 0.061 \\
\hline Steaming and boiling & $41(21.1)$ & $9(22.0)$ & \\
\hline Stir frying and stewing & $138(71.1)$ & $24(58.5)$ & \\
\hline
\end{tabular}


Proceeding of the $5^{\text {th }}$ International Conference on Public Health, Vol. 5, Issue 1, 2019, pp. 27-36

Deep frying and stir frying $\quad 15(7.7) \quad 8(19.5)$

The most food they eat in Taiwan

Taiwanese foods

$146(75.3)$

$30(73.2)$

Indonesia foods / western foods

$48(24.7)$

$11(26.8)$

Preference of Taiwanese food ${ }^{c}$

$\begin{array}{lll}\text { No/Slightly } & 79(40.7) & 25(61.0) \\ \text { Yes } & 115(59.3) & 16(39.0)\end{array}$

Self-perceived acculturation

Self-perceived feeling in Taiwan ${ }^{c}$

No changes

Feeling sad and weak

Feeling happier and energetic

Self-perceived eating habits in Taiwan ${ }^{c}$

No changes

Worse

Better

Self-perceived cooking method used in Taiwan $^{c}$

Less healthy / no changes
Healthier

Self-perceived health status in Taiwan ${ }^{c}$

No changes

Worse

Better
0.006

$\begin{array}{ll}68(35.1) & 13(31.7) \\ 30(15.5) & 15(36.6) \\ 96(49.5) & 13(31.7)\end{array}$

96 (49.5)

79 (40.7)

22 (53.7)

31 (16.0)

9 (22.0)

84 (43.3)

$10(24.4)$

0.080

0.028

.

1.000

$81(41.8) \quad 17(41.5)$

$113(58.2) \quad 24(58.5)$

18 (43.9)

13 (31.7)

17 (8.8)

$10(24.4)$

\footnotetext{
${ }^{a}$ mean $(+\mathrm{SD})$

${ }^{\mathrm{b}}$ median $(25,75$ percentile $)$

${ }^{\mathrm{c}} \mathrm{n}(\%)$

* p-values are based on chi-square test for categorical variables, mann-whitney u-test for continous variables

r Fatigue status was defined by BFI score $>1$

$\uparrow$ Depressive symptoms status was defined by BDI-II score $>17$

+ Erythropoiesis: normal: $\mathrm{Hb}>12 \mathrm{~g} / \mathrm{dL}$, anemia: $\mathrm{Hb}<12 \mathrm{gr} / \mathrm{dL}$
} 